\title{
WELDABILITY OF HIGH-STRENGTH MICROALLOYED STEEL S460M
}

\author{
V.D. POZNYAKOV, S.L. ZHDANOV, A.V. ZAVDOVEEV, A.A. MAKSIMENKO and T.G. SOLOMIJCHUK \\ E.O. Paton Electric Welding Institute, NASU \\ 11 Kazimir Malevich Str., 03680, Kiev, Ukraine. E-mail: office@paton.kiev.ua
}

\begin{abstract}
The structural steels of strength class S350 and higher are widely used in manufacture of metal structures of different purpose. Their application allows significant reducing the total metal consumption of structures as compared to the products of steels of grades St.3 and 09G2S. In the present work the influence of welding thermal cycles on the properties and structure of HAZ metal, resistance of joints to cold crack formation is considered. The selection of welding consumables for steels of strength class S490 was justified and the change of mechanical properties of welded joints was analyzed. It was revealed that with increase in the rate of cooling the HAZ metal of model specimens-simulators, the strength characteristics increase, and the ductile ones decrease. Thus, the values of impact toughness are sharply reduced at the cooling rate of $3{ }^{\circ} \mathrm{C} / \mathrm{s}$. It is possible to increase greatly the resistance to cold crack formation in technological samples of steel S460M at the increased content of diffusion hydrogen in the deposited metal by decreasing the value of residual stresses in welded joints to the level not exceeding $0.5 \sigma_{\mathrm{y}}$ of steel ( $\left.\leq 235 \mathrm{MPa}\right) .13 \mathrm{Ref} ., 1$ Table, 9 Figures.
\end{abstract}

Ke y w ord s: high-strength steel, welding thermal cycle, cooling rate, mechanical properties, cold cracks, diffusion hydrogen, brittle fracture

The development of modern industry, building industry and power engineering specifies new requirements to metal structures in reducing the metal consumption and increasing their reliability [1-4]. Such effect can be achieved by applying new high-strength steels with the yield strength of higher than $390 \mathrm{MPa}$. The structural steels of strength class S350 and higher are applied in bridge construction, construction of tall buildings, wind power engineering for construction of supports of windmills, as well as in manufacture of metal structures of railway freight transport $[1,5]$. The application of high-strength rolled metal allows reducing the total metal consumption of structures to $80 \%$ as compared to the products of steels of grades St.3 and 09G2S [6].

To develop steels of improved strength in the modern production, two approaches are mainly used. The first one consists in application of alloying elements increasing the strength characteristics. But this method leads to a significant increase in the cost of manufactured rolled metal. The alternative of alloying is the thermal deformational hardening of metal or controllable rolling with the subsequent heat treatment. Such steels include high-strength low-alloyed steel S460M (strength class S490), microalloyed with niobium and vanadium. According to the data of the standard EN 10025-4 the steel has the following mechanical properties: $\sigma_{\mathrm{y}}>460 \mathrm{MPa}, \sigma_{\mathrm{t}}=540-720 \mathrm{MPa}, \delta_{5}>18 \%$, $K C V_{-40}>27 \mathrm{~J} / \mathrm{cm}^{2}$. Such characteristics are provided by a finely dispersed structure obtained after controllable rolling.

In the manufacture of structures of low-alloyed steels of such strength class the problem of study of their weldability becomes urgent [7]. It is known that in the process of welding the metal of heat affected zone (HAZ) undergoes structural transformations which lead to changes in mechanical properties [8]. In this connection in the present paper the influence of welding thermal cycles (WTC) on the properties and structure of HAZ metal, resistance to cold crack formation are considered. The welding consumables for steel S460M of strength class S490 were proposed, the mechanical properties of welded joints and their resistance to brittle fracture were investigated.

The procedure of investigations. For experiments the structural steel S460M of $16 \mathrm{~mm}$ thickness of the following composition was selected, wt.\%: $0.15 \mathrm{C}$; $0.23 \mathrm{Si}, 1.3 \mathrm{Mn} ; 0.09 \mathrm{Cr} ; 0.019 \mathrm{Ni} ; 0.01 \mathrm{~V} ; 0.05 \mathrm{Nb}$; $0.025 \mathrm{Al} ; 0.007 \mathrm{~N}_{2} ; 0.013 \mathrm{~S} ; 0.017 \mathrm{P}$. The mechanical properties of the investigated steel S460M are the following: $\sigma_{\mathrm{y}}=480 \mathrm{MPa} ; \sigma_{\mathrm{t}}=600 \mathrm{MPa} ; \delta_{5}=27 \%$; $\psi=58 \%$.

As the criteria of WTC the metal cooling rate in the temperature range of $600-500{ }^{\circ} \mathrm{C}\left(w_{6 / 5}\right)$ was accepted. According to the results of investigations the cooling rates were determined at which the decrease in the values of strength, ductility, and impact toughness of HAZ metal occurs as compared to the 
requirements specified to welded joints. The investigations were carried out using the model specimens of the size $120 \times 12 \times 12 \mathrm{~mm}$, which were heat treated in accordance with the thermal cycles of welding in the installation MSR-75 [9]. The heat treatment process consisted in the following. At first, the specimens were heated using current, passing through them, to the temperatures of $1200-1300{ }^{\circ} \mathrm{C}$, which are characteristic for the area of overheating the HAZ welded joints. The heating rate of specimens was 150 $170^{\circ} \mathrm{C} / \mathrm{s}$, which corresponds to heating conditions in the metal of heat affected zone in arc welding processes. At this temperature, the specimens were held for about two seconds and then they were subjected to a forced cooling. For testing on static tension the steel specimens were mechanically manufactured (type II) according to GOST 6996-96 (3 specimens for each cooling rate). The tests were carried out in accordance with GOST 6996-66 at room temperature. For tests on impact toughness the specimens of the type XI were manufactured, which were tested at the temperatures of $20,-20$ and $-40^{\circ} \mathrm{C}$.

The investigation of susceptibility of steel S460M to delayed fracture was performed using the method Implant in the specialized installation, designed at the E.O. Paton Electric Welding Institute of the NAS of Ukraine [10]. The cooling rate of HAZ metal was changed due to different initial temperature of plates, which, depending on technological variant of welding, ranged from 20 to $90{ }^{\circ} \mathrm{C}$. For this purpose, preheating was used. Such approach allowed changing the cooling rate of welded joints $w_{6 / 5}$ in the range of $21-14{ }^{\circ} \mathrm{C} / \mathrm{s}$. The content of diffusion hydrogen in the deposited metal (evaluated by the method of pencil samples using the mixture of glycerine and distilled water in the ratio of 1:4 as a sealing liquid) was changed using electrodes with different humidity of coatings. For this purpose they were wetted and calcinated at different temperatures. The static loading of specimens at the speed of $10 \mathrm{MPa} / \mathrm{s}$ was started after their cooling to the temperature of $150-100^{\circ} \mathrm{C}$, and as the value of resistance of welded joints to cold crack formation the critical stresses $\sigma_{\text {cr }}$ were accepted, at which the specimen was not fractured within 24 hours.

As far as one of the main factors influencing the resistance of welded joints to cold crack formation, is the level of residual stresses, the investigations were carried out using butt technological samples with a regulated hardness. This allowed regulating only stress state of technological samples and evaluating its influence on stability of joints against cold cracks formation without changing the hydrogen and struc- tural factors influencing the formation of cold cracks in welded joints.

To carry out investigations in the work the technological sample was selected representing a massive plate of the size of $400 \times 400 \mathrm{~mm}$ and the thickness of 40-60 mm, on which two plates are installed and welded-on around the whole perimeter with a leg of $12 \mathrm{~mm}$, of which a reference welded joint is formed. In the V-shaped butt joint of steel S460M the presence of 1.5-2.0 mm gap and blunting of 3.0-4.0 mm are provided to ensure a technological lack of penetration, which is a stress concentrator and initiates the crack formation. The level of hardness was determined by the width of plates, of which the reference butt joint is composed. According to the methods of investigations the welding of butt joints of the plates of 50, 100 and $150 \mathrm{~mm}$ width, and of $16 \mathrm{~mm}$ thick was performed. The total width of the joints in this case was 100, 200 and $300 \mathrm{~mm}$.

The investigations of the past years [11] which were performed on multilayer joints, indicate that in the process of formation of welded joints, the significant transverse shortening of weld and HAZ metal along the whole length of specimen occurs. The most intensive shortening was observed in a central part of the weld after producing the root beads. According to these data, the highest value of displacements was observed in the hard specimens of $300 \mathrm{~mm}$ width $(\Delta L \approx 0.45 \mathrm{~mm})$. In the narrower samples of 200 and $100 \mathrm{~mm}$ width the running of plastic deformation processes is complicated, and therefore the maximum values of cross shortening in them are lower: $\Delta L \approx 0.4 \mathrm{~mm}$ and $0.33 \mathrm{~mm}$, respectively. It contributes to formation of a higher level of residual welding stresses in the specimens with the maximum rigidity of fixing (fixing base $B=100 \mathrm{~mm}$ ). With increase in fixing base $B$ from 100 to $300 \mathrm{~mm}$, the level of residual stresses in the weld metal of joints decreases from $0.8-0.9$ to $0.4-0.5$ of yield strength of weld metal. The manual arc welding of joints of steel S460M was performed using electrodes UONI-13/55 and FOX EV-50 of $4.0 \mathrm{~mm}$ diameter at the mode: $I_{\mathrm{w}}=160$ $170 \mathrm{~A} ; U_{\mathrm{a}}=24-25 \mathrm{~V} ; v_{\mathrm{w}}=8.5-9.0 \mathrm{~m} / \mathrm{h}$. For the mechanized welding of joints of this steel the solid wires St-08G2S and G3Sil and the flux-cored wire of grade Megafil 821R of $1.2 \mathrm{~mm}$ diameter were applied. The welding was performed in the mixture of gases $82 \%$ $\mathrm{Ar}+18 \% \mathrm{CO}_{2}$ at the modes: $I_{\mathrm{w}}=170-190 \mathrm{~A} ; U_{\mathrm{a}}=$ $=26-28 \mathrm{~V} ; v_{\mathrm{w}}=11.5-12 \mathrm{~m} / \mathrm{h}$ using the solid wire and at $I_{\mathrm{w}}=220-240 \mathrm{~A} ; U_{\mathrm{a}}=28-30 \mathrm{~V} ; v_{\mathrm{w}}=14-15 \mathrm{~m} / \mathrm{h}$ using flux-cored wire.

To determine the values of the critical stress intensity factor $K_{1 C}$ and the crack opening displacement $\delta_{c}$ the specimens of rectangular cross-section of the size 
$10 \times 20 \times 90 \mathrm{~mm}$ with a notch of $7 \mathrm{~mm}$ length and fatigue crack of $3 \mathrm{~mm}$ length were applied. These specimens were tested at three-point bending in the temperature range from 20 to $-40{ }^{\circ} \mathrm{C}$. Using the criteria of fracture mechanics [12] the evaluation of resistance to brittle fracture of welded joints of steel S460M was carried out depending on the applied welding consumables and methods. The tip of fatigue crack in one specimens was located in the weld metal, and in the other one - in the HAZ metal. For comparison, the specimens were manufactured of steel S460M base metal.

Obtained results and discussion. Effect of welding thermal cycle on structure and properties. In the present work the structure and mechanical properties of thermomechanically hardened steel S460M (strength class S440), manufactured according to DSTU EN 10025-4:2007 at the Mariupol Metallurgical Plant were studied. Due to thermomechanical rolling in the temperature range of $900-700{ }^{\circ} \mathrm{C}$ with the controllable cooling the ferrite-pearlite banded structure with the hardness $H V$-195 (Figure 1) is formed in steel S460M.

The mark of grain corresponds to No. 10 according to GOST 5639-82, and banding mark - to the number 5 on the scale 3 of GOST 5640-68. The contamination with non-metallic inclusions, such as silicates, aluminum silicates, sulfides and oxysulfides, corresponds to the mark No.1 in accordance with GOST 1778-70.

The values of impact toughness of steel S460M greatly exceed the standard values of $\mathrm{KCV}_{-40} \geq$ $\geq 34 \mathrm{~J} / \mathrm{cm}^{2}$, even at the test temperature of $-60{ }^{\circ} \mathrm{C}$ $\left(K C V_{-60}=76 \mathrm{~J} / \mathrm{cm}^{2}\right)$.

In their turn, the dependencies characterizing the changes of values of strength and ductility in the simulated HAZ metal of steel S460M under the influence of WTC, are shown in Figure 2, $a, b$. The results of investigations evidence, that with the change in cooling rate in the temperature range of $600-500{ }^{\circ} \mathrm{C}\left(w_{6 / 5}\right)$ from 3 to $25^{\circ} \mathrm{C} / \mathrm{s}$ the values of strength of HAZ metal increase as compared to the initial state, namely $\sigma_{y}$ from 490 to $810 \mathrm{MPa}$ and $\sigma_{\mathrm{t}}$ from 600 to $1000 \mathrm{MPa}$. At the same time, the ductile properties of the simulated HAZ metal are deteriorated as compared to the initial state. Especially this refers the values of elongation, which are reduced by $2.5-3.0$ times, at the same time the values of relative reduction in area are decreased by $15-20 \%$.

In the tests of specimens with a sharp V-notch on impact bending it was revealed that the impact toughness of HAZ metal of steel S460M decreases in relation to the base metal (Figure 2,c). The most significant decrease in $K C V$ values by $4-9$ times is

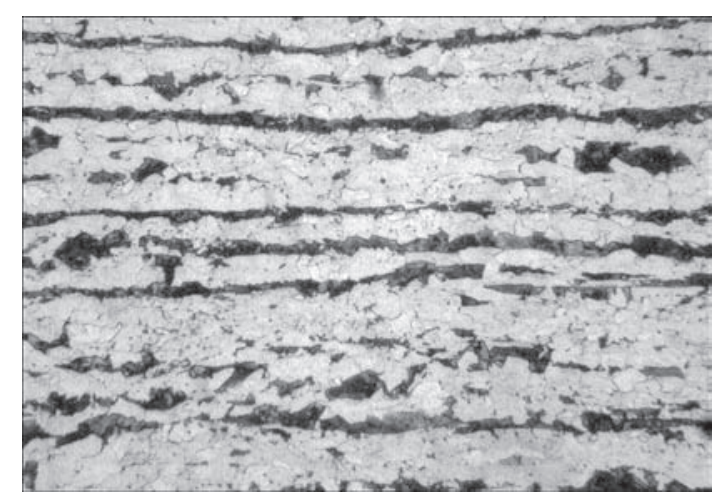

Figure 1. Microstructure $(\times 500)$ of steel S460M

observed in specimens, which cooled down at the rate $w_{6 / 5}=3{ }^{\circ} \mathrm{C} / \mathrm{s}$ (from 111 to $33 \mathrm{~J} / \mathrm{cm}^{2}$ at the test temperature of $20^{\circ} \mathrm{C}$, from 109 to $15 \mathrm{~J} / \mathrm{cm}^{2}$ at the temperature of $-20^{\circ} \mathrm{C}$ and from 95 to $10 \mathrm{~J} / \mathrm{cm}^{2}$ at the temperature of $-40{ }^{\circ} \mathrm{C}$ ). With increase in cooling rate to $10^{\circ} \mathrm{C} / \mathrm{s}$, they are increased to the values of $K C V_{-40}=27 \mathrm{~J} /$ $\mathrm{cm}^{2}$, and then slightly decrease and at $w_{6 / 5}=25^{\circ} \mathrm{C} / \mathrm{s}$ they are: $K C V_{20}=50 \mathrm{~J} / \mathrm{cm}^{2}, K C V_{-20}=30 \mathrm{~J} / \mathrm{cm}^{2}$ and $K C V_{-40}=20 \mathrm{~J} / \mathrm{cm}^{2}$ (for comparison of the values of impact toughness of steel S460M tests at the test temperatures ranging from 20 to $-40{ }^{\circ} \mathrm{C}$ are in the range of $95-110 \mathrm{~J} / \mathrm{cm}^{2}$ ).
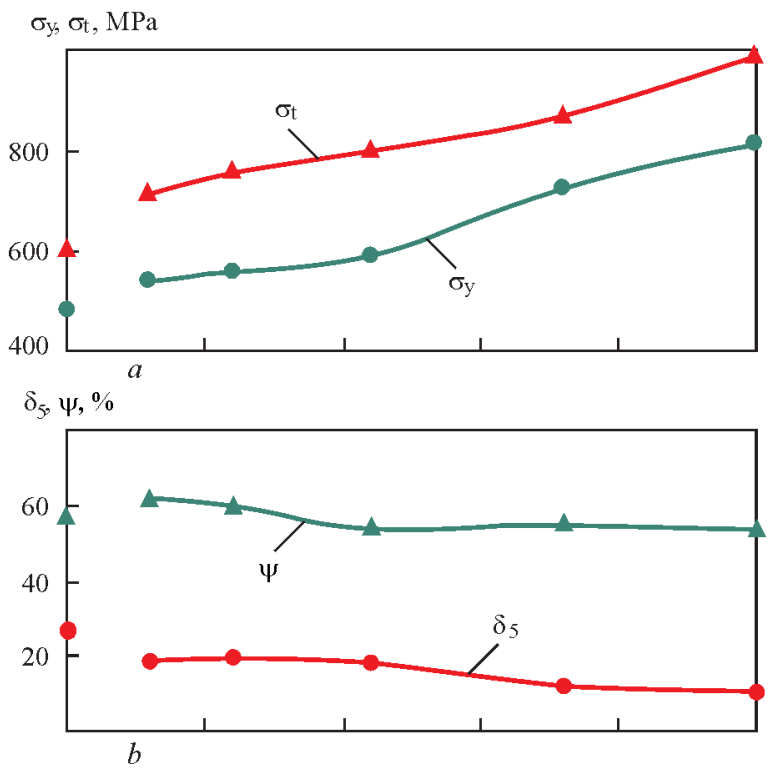

$K C V, \mathbf{J} / \mathrm{cm}^{2}$

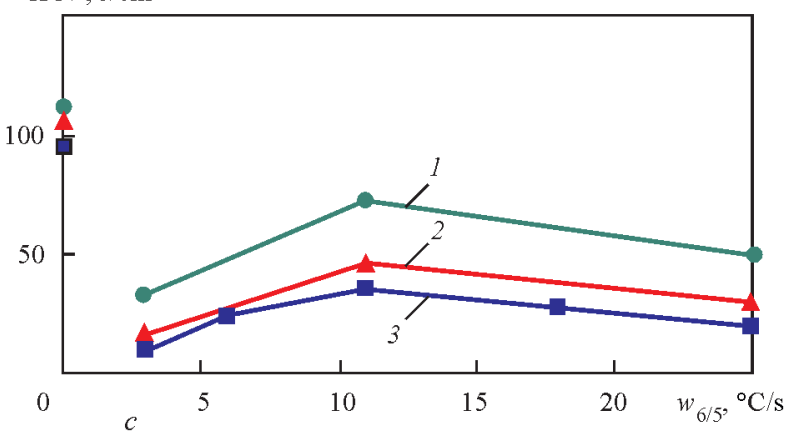

Figure 2. Influence of cooling rate on strength $(a)$, ductility $(b)$ and impact toughness at the test temperature: $1-20 ; 2--20$; $3--40{ }^{\circ} \mathrm{C}$ (c) of simulated HAZ metal of steel S460M 


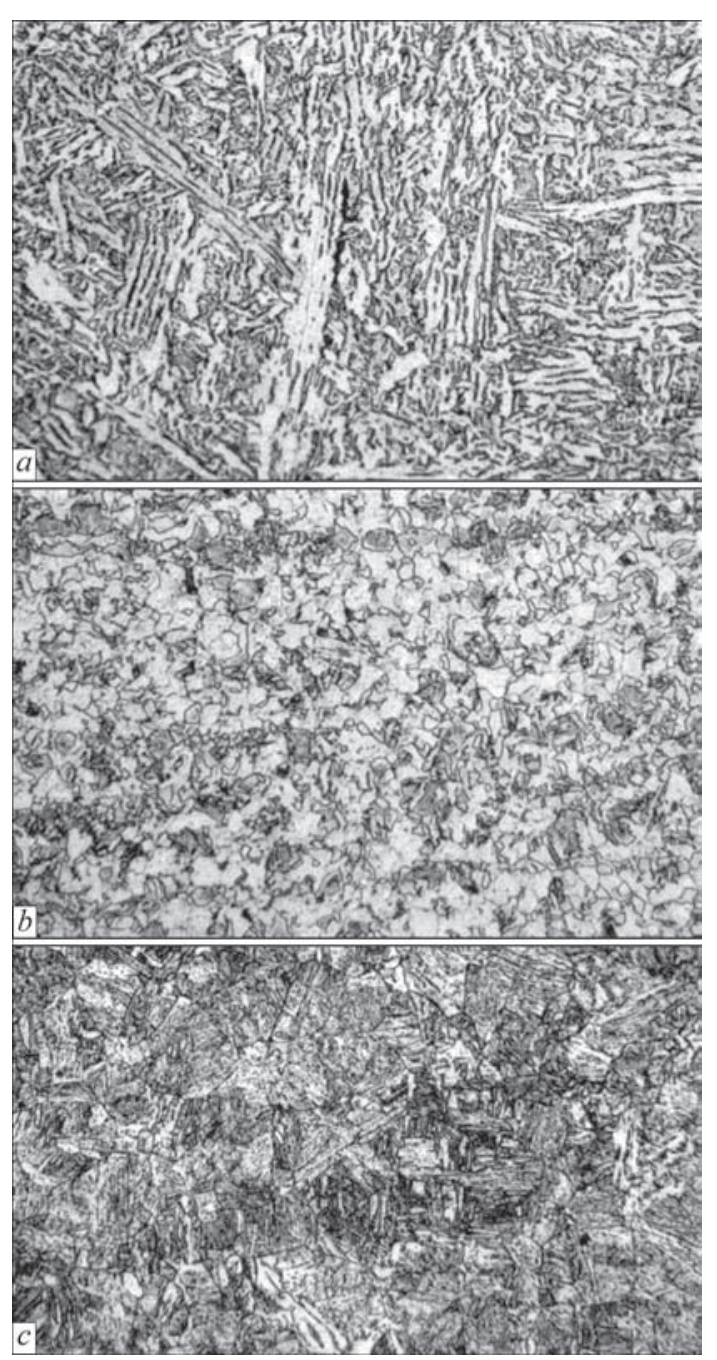

Figure 3. Microstructure $(\times 500)$ of HAZ metal of model specimens of steel S460M: $a-w_{6 / 5}=3 ; b-10 ; c-25^{\circ} \mathrm{C} / \mathrm{s}$

Such changes in mechanical properties of HAZ metal of steel S460M are caused by different structural transformations in the range of investigated cooling rates. This is evidenced by the results of metallographic examinations.

It was found by the metallographic examinations that in the overheating area in the HAZ metal of steel S460M at the cooling rate $w_{6 / 5}=3{ }^{\circ} \mathrm{C} / \mathrm{s}$ the structure was formed consisting of different morphological forms of ferrite and a small amount of pearlite (Figure $3, a$ ). The hardness of such metal amounts to HV1$2400 \mathrm{MPa}$ and the banding of structure, which was observed in it before the treatment by a thermal cycle, disappears completely.

At the increase in $w_{6 / 5}$ to $10^{\circ} \mathrm{C} / \mathrm{s}$ the equiaxial ferrite-pearlite fine-dispersed structure with the areas of bainite component is formed. The grain size in accordance with GOST 5639-82 corresponds to the mark 9 on the scale 1 , and the hardness almost does not change, although the values of strength grow approximately by $100 \mathrm{MPa}$.
At the further increase in cooling rate to $w_{6 / 5}=$ $=25^{\circ} \mathrm{C} / \mathrm{s}$ in the simulated HAZ metal the structure is formed, consisting of mixture of upper and lower bainite and a small amount of martensite and ferrite. Due to that the hardness of metal is increased to HV12800-2960 MPa, which in its turn leads to growth of values of its static strength and decrease in ductile properties.

Resistance of welded joints to cold crack formation. It is known that the following factors have a decisive influence on cold crack formation: hardening structures in the HAZ and weld metal, hydrogen in these areas of welded joint and the stresses of the I type caused by the welding process and rigidity of joints fixing.

During welding in the HAZ metal of low-carbon heat strengthened steels the structures are formed, the ductility of which sharply decreases with increase in hydrogen content. The hydrogen is released in the imperfections of metal structure (pores, cracks along the grain boundaries, etc.) and causes arising of high local stresses. At the mutual effect of stresses caused by the welding process, structural transformations and hydrogen in the HAZ metal, the cold cracks can occur.

The simplest solution to the problem of reducing of diffusion hydrogen concentration in the weld metal is the use of low-hydrogen welding consumables, namely, electrodes with a basic coating for manual arc welding and flux-cored wires of a basic type for mechanized welding in shielding gases.

Regarding the possibility of removing diffusion hydrogen from welded joints, it is necessary to note the effectiveness of applying preheating or performing this procedure after welding. If the purpose of preheating is decrease in cooling rate and, at the same time, increase in cooling period in the temperature range of $800-500{ }^{\circ} \mathrm{C}$, then the preheating after welding delays the cooling rate of HAZ metal in the temperature range of $300-100{ }^{\circ} \mathrm{C}$, which allows removing diffusion hydrogen from welded joints to the greater extent.

It was found that at low concentrations of diffusion hydrogen in the deposited metal (Figure 4), and namely at $[\mathrm{H}]_{\text {diff }}=1.6 \mathrm{ml} / 100 \mathrm{~g}$, even during welding without preheating $\left(w_{6 / 5}=21{ }^{\circ} \mathrm{C} / \mathrm{s}\right)$ the steel $\mathrm{S} 460 \mathrm{M}$ is not subjected to a delayed fracture. This is evidenced by the fact that within $24 \mathrm{~h}$ after loading the specimens, the cracks were not formed in them even in the case when the level of stresses was approaching the yield strength of HAZ metal of steel.

With increase in the content of diffusion hydrogen in the deposited metal from 1.6 to $3.8 \mathrm{ml} / 100 \mathrm{~g}$, the risk of cold crack formation in the HAZ metal of welded joints increases. To improve the resistance of 
welded joints to cold crack formation is possible by using preheating. Thus, at $[\mathrm{H}]_{\text {diff }}=3.8 \mathrm{ml} / 100 \mathrm{~g}$, the preheating $T_{\mathrm{ph}}$ to the temperature of $60^{\circ} \mathrm{C}$ allows increasing the level of critical stresses to $350 \mathrm{MPa}$, and at $T_{\mathrm{ph}}=90^{\circ} \mathrm{C}$ - to $\sigma_{\mathrm{cr}}=390 \mathrm{MPa}$.

At the limited content of diffusion hydrogen in the deposited metal the steel S460M does not reveal susceptibility to a delayed fracture. Accordingly, the welded joints of these steels under the given conditions should have a good resistance to cold crack formation. As the results of testing technological samples (Table) show, during welding without preheating in the joints of steel S460M regardless of rigidity of their fixture, it is possible to eliminate the probability of cold crack formation, under the conditions when the content of diffusion hydrogen in the deposited metal does not exceed $1.6-1.7 \mathrm{ml} / 100 \mathrm{~g}$ at $Q_{\mathrm{w}}=$ $=11-13 \mathrm{~kJ} / \mathrm{cm}$ and $3.0 \mathrm{ml} / 100 \mathrm{~g}$ at $Q_{\mathrm{w}}=15-16 \mathrm{~kJ} / \mathrm{cm}$ and higher. This is well correlated with the results of tests by the Implant method.

The cracks in the technological samples of steel S460M of width B $=100 \mathrm{~mm}$ were observed in the cases when welding was performed without preheating $\left(w_{6 / 5}=21^{\circ} \mathrm{C} / \mathrm{s}\right)$ and the content of diffusion hydrogen in the deposited metal was $5.3 \mathrm{ml} / 100 \mathrm{~g}$. In the technological samples with the fixing base of $100 \mathrm{~mm}$ the crack which passed in the welded joint along the entire length and escaped to the surface of a root weld, began its formation already within 2 hours after the welding completion. This was evidenced by the signals of acoustic emission which were fixed using IKD-128 device [13]. Within 4 hours the crack was visually seen on the weld surface.

It is possible to improve significantly the resistance to cold crack formation in the technological samples of steel S460M at the increased content of diffusion

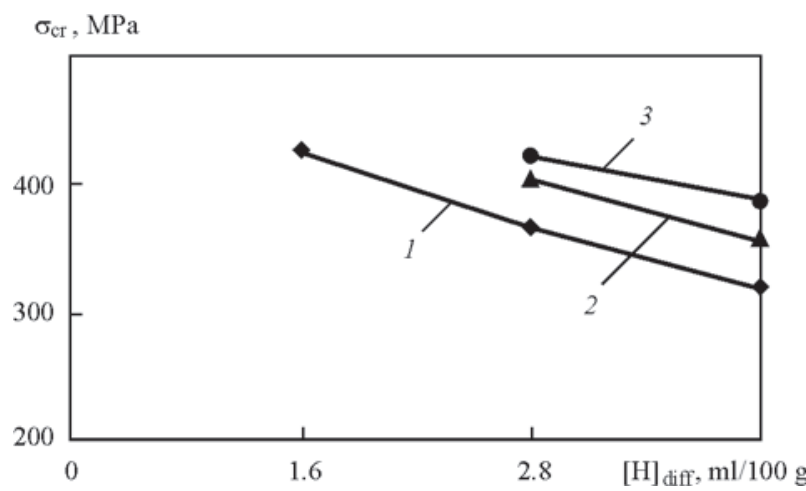

Figure 4. Influence of diffusion hydrogen on resistance to a delayed fracture of HAZ metal of steel S460M: 1 - without preheating; $2-T_{\mathrm{ph}}=60 ; 3-90{ }^{\circ} \mathrm{C}$

hydrogen in the deposited metal by decreasing the value of residual stresses in welded joints to the level not exceeding $0.5 \sigma_{\mathrm{y}}$ of steel $(\leq 235 \mathrm{MPa})$. Namely, such a level of stresses is formed in the weld metal of joints of steel S460M produced using electrodes UONI 13/55 at the fixing base of $200 \mathrm{~mm}$ (see Table).

Structure and mechanical properties of steel S460M welded joints. The analysis of test results shows that according to the values of static strength and ductility those welds correspond to the requirements of steel S460M $\left(\sigma_{\mathrm{y}} \geq 460 \mathrm{MPa}, \sigma_{\mathrm{t}} \geq 540\right.$ $720 \mathrm{MPa}, \delta_{5} \geq 17 \%$ ) according to EN 10025-4:2007, which were produced using electrodes FOX EV 50, solid wire G3Sil and flux-cored wire of grade Megafil 821R.

Somewhat lower by $5-13 \%$ than the standard indicators is the value of yield stresses of weld metal of steel S460M welded joints produced using electrodes UONI-13/55 and the wire Sv-08G2S, which are, respectively, 440 and $400 \mathrm{MPa}$. At the same time, the values of tensile strength $\left(\sigma_{\mathrm{t}} \approx \sim 556 \mathrm{MPa}\right)$ and elongation $\left(\delta_{5}=31 \%\right)$ exceed their minimum standard values for steel.

Results of investigation of technological samples «hard welding» of steel S460M

\begin{tabular}{|c|c|c|c|c|c|c|c|c|c|c|}
\hline \multirow{2}{*}{$\begin{array}{l}\text { Width } B \text {, } \\
\text { mm }\end{array}$} & \multirow{2}{*}{ Welding consumables } & \multicolumn{4}{|c|}{ Welding modes } & \multirow{2}{*}{$T_{\mathrm{h}},{ }^{\circ} \mathrm{C}$} & \multirow{2}{*}{$\begin{array}{c}{[\mathrm{H}]_{\text {diff }},} \\
\mathrm{ml} / 100 \mathrm{~g}\end{array}$} & \multicolumn{3}{|c|}{ Presence of cracks, $\%$} \\
\hline & & $I_{\mathrm{w}}, \mathrm{A}$ & $U_{\mathrm{a}}, \mathrm{V}$ & $v_{\mathrm{w}}, \mathrm{m} / \mathrm{h}$ & $Q_{\mathrm{w}}, \mathrm{kJ} / \mathrm{cm}$ & & & Root & Middle & Surface \\
\hline 100 & $\begin{array}{l}\text { Electrodes UONI-13/55 of } 4 \\
\text { mm diameter }\end{array}$ & $150-170$ & $24-26$ & $8-10$ & $12.5-11.0$ & 20 & 5.3 & 100 & 100 & 100 \\
\hline 200 & $\begin{array}{l}\text { Electrodes UONI-13/55 of } 4 \\
\text { mm diameter }\end{array}$ & $150-170$ & $24-26$ & $8-10$ & $12.5-11.0$ & 20 & 5.3 & 0 & 0 & 0 \\
\hline 100 & $\begin{array}{l}\text { Electrodes UONI-13/55 of } 4 \\
\text { mm diameter }\end{array}$ & $150-170$ & $24-26$ & $8-10$ & $12.5-11.0$ & 60 & 5.3 & 0 & 0 & 0 \\
\hline 100 & $\begin{array}{l}\text { Wire Sv-08G2S of } 1.2 \mathrm{~mm} \\
\text { diameter in } \mathrm{CO}_{2}\end{array}$ & $180-200$ & $28-30$ & $13-14$ & $13.0-11.0$ & 20 & 1.0 & 0 & 0 & 0 \\
\hline 100 & $\begin{array}{l}\text { Wire Sv-08G2S of } 1.2 \mathrm{~mm} \\
\text { diameter in } \mathrm{CO}_{2}\end{array}$ & $220-240$ & $30-32$ & $6-7$ & $33.0-28.4$ & 20 & 1.0 & 0 & 0 & 0 \\
\hline 100 & $\begin{array}{l}\text { Wire Megafil } 821 \mathrm{R} \text { of } 1.2 \mathrm{~mm} \\
\text { diameter in } \mathrm{CO}_{2}\end{array}$ & $240-260$ & $28-30$ & $17-18$ & $15.8-14.8$ & 20 & 3.0 & 0 & 0 & 0 \\
\hline
\end{tabular}




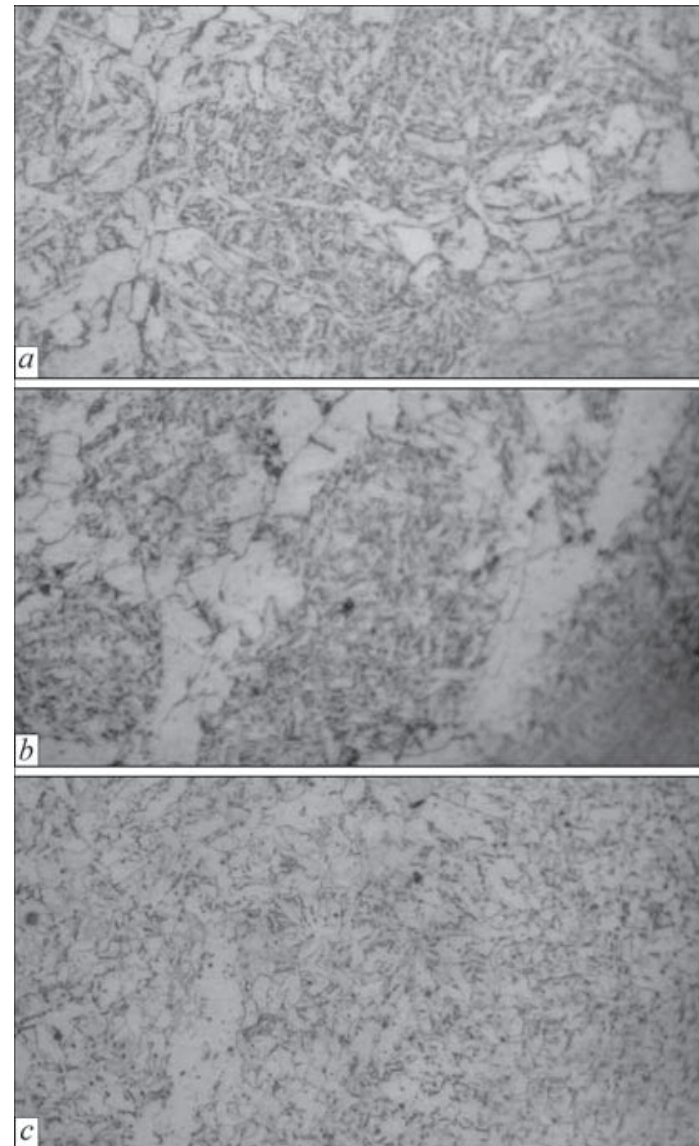

Figure 5. Microstructure $(\times 400)$ of metal of steel S460M welded joints produced using UONI-13/55 (a), solid wire Sv-08G2S (b) and flux-cored wire Megafil 821R (c)

The high values of yield strength and tensile strength relative to the welds, produced using electrodes UONI-13/55 and the wire Sv-08G2S belong to the metal deposited using electrodes FOX EV-50, and also in gas mixture using solid wire G3Sil and flux-cored wire of grade Megafil 821R, respectively. However, although the values of elongation in mechanized welding are lower than the similar values for the metal, deposited using covered electrodes, they exceed the standard values specified to the base metal.

There is the fact which attracts attention that the values of strength and ductility of weld metal produced using electrodes UONI-13/55 and solid wire Sv-08G2S, are sufficiently close. This is evidenced by the results of metallographic investigations. They showed that the structure of such welds (Figure $5, a, b$ ) is finely dispersed and consists mainly of polygonal ferrite with negligible pearlite inclusions on the boundaries of ferrite grains with the hardness $H V-191-200$. But in welding using flux-cored wire Megafil 821R the structure of weld metal is composed primarily of structurally free ferrite with a low content of coarse acicular ferrite (Figure 5). The hardness in the given case amounts to $H V$-210, which results in increasing values of strength and decrease in plastic properties.

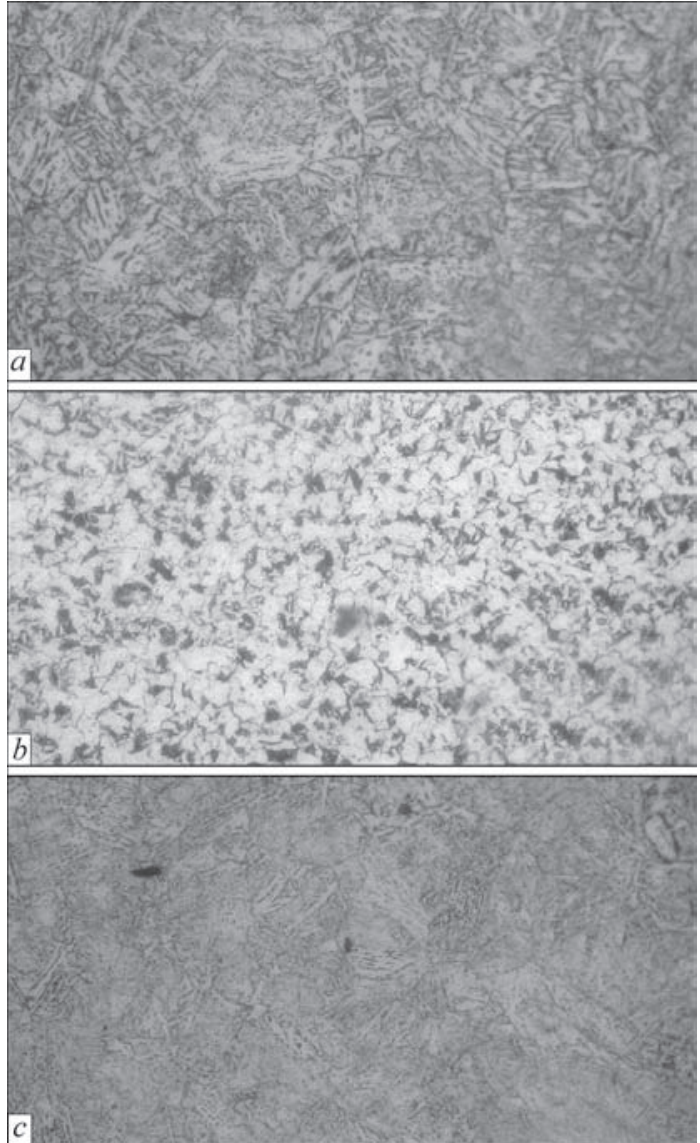

Figure 6. Microstructure $(\times 400)$ of HAZ metal in the area of overheating of steel S460M welded joints produced using UONI13/55 (a), solid wire Sv-08G2S (b) and flux-cored wire Megafil $821 \mathrm{R}(c)$

The structure of metal in the area of overheating the HAZ of welded joints of steel S460M is identified as a coarse ferrite-pearlite with approximately equal ratio of ferrite and pearlite components and the hardness $H V-205-221$ (Figure 6, $a-c$ ).

According to the results of tests of specimens with a sharp notch, it was revealed, that all the mentioned steel-welding consumable combinations are capable to provide impact toughness of both the weld and HAZ metal of welded joints of steel S460M at the level of Euronorm requirements, namely $\mathrm{KCV}_{-40} \geq$ $\geq 27 \mathrm{~J} / \mathrm{cm}^{2}$ (Figure 7).

Resistance of steel S460M welded joints to brittle fracture. The brittle fracture occurs in welded joints in the zones of small volume of metal where plastic deformations are localized. The zones of fracture can be the metal, near which there are such defects as cracks, lacks of fusion, pores, slag inclusions, undercuts. These defects (especially tiny ones) can not always be detected by the methods of non-destructive testing such as ultrasonic and magnetic flaw detection, radiography, etc. During static and cyclic loading of welded structures these defects can initiate propagation of cracks in the metal, which during 

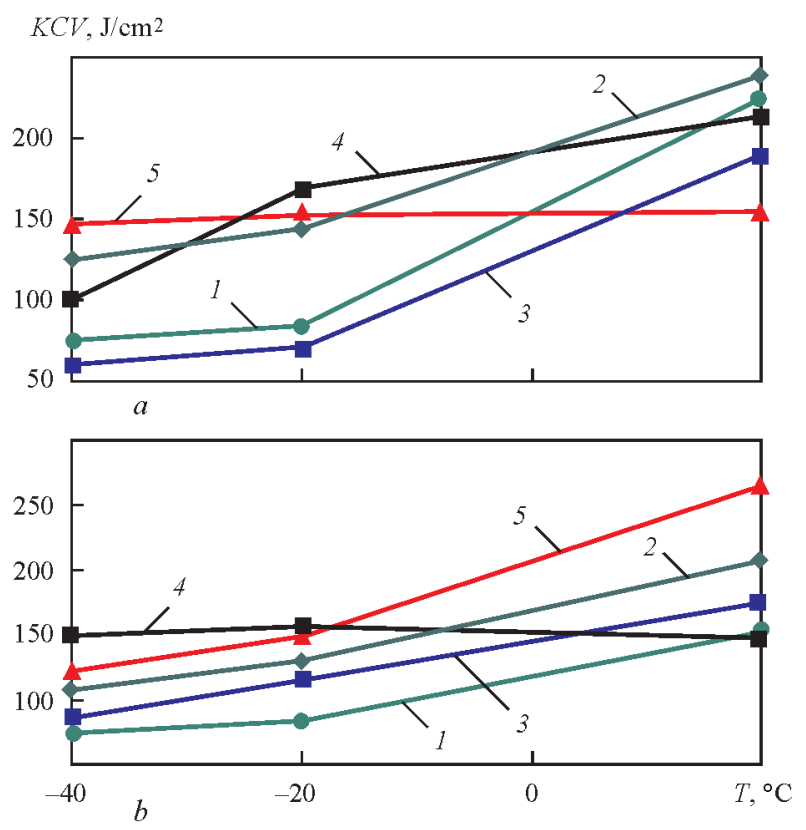

Figure 7. Impact toughness of weld metal $(a)$ and HAZ metal $(b)$ of steel S460M welded joints produced using electrodes UONI13/55 (1) and FOX EV-50 (2); solid wire Sv-08G2S (3), G3Sil (4) and flux-cored wire Megafil 821R (5)

operation (especially under the conditions of sub-zero temperatures) cause their fracture.

According to the methods of fracture mechanics the critical stress intensity factor $K_{1 C}$ is used for evaluation of sensitivity of metal to stress concentration under the conditions of plane deformation at static loading (more often bending). At the increase in values $K_{1 C}$ the sensitivity of metal to stress concentration is reduced. The second criterion of fracture mechanics is the crack opening displacement $\delta_{c}$, which is a deformation criterion and is used for evaluation of resistance of metal to the start of crack movement. With its help the evaluation of metal resistance to brittle fracture is carried out under the conditions of large plastic deformation, when the crack in its tip reaches critical values $\delta_{c}$ and begins a rapid propagation, using the energy released at its further growth [11].

It was revealed by the carried out investigations that for the weld metal, produced using electrodes UONI-13/55 at the test temperature of $-40,-20$ and $20{ }^{\circ} \mathrm{C}$, the average values $K_{1 C}$ are respectively equal to $42.1 ; 52.2$ and $77.2 \mathrm{MPa} \sqrt{\mathrm{m}}$, and for the metal of weld, produced using flux-cored wire of grade Megafil $821 \mathrm{R}$ under the similar test temperatures, the average values $K_{1 C}$ are respectively equal to $49.1 ; 58.5$ and $78.6 \mathrm{MPa} \sqrt{\mathrm{m}}$, i.e. they are increased by $14.3 ; 10.8$ and $1.8 \%$ (Figure 8 ).

For HAZ metal of welded joints, produced using electrodes UONI $13 / 55$, at the test temperature of $-40,-20$ and $20{ }^{\circ} \mathrm{C}$ the average values $K_{1 C}$ are, respectively. equal to $41.4,52.3$ and $73.2 \mathrm{MPa} \sqrt{\mathrm{m}}$, and for HAZ metal of welded joints, produced using flux-
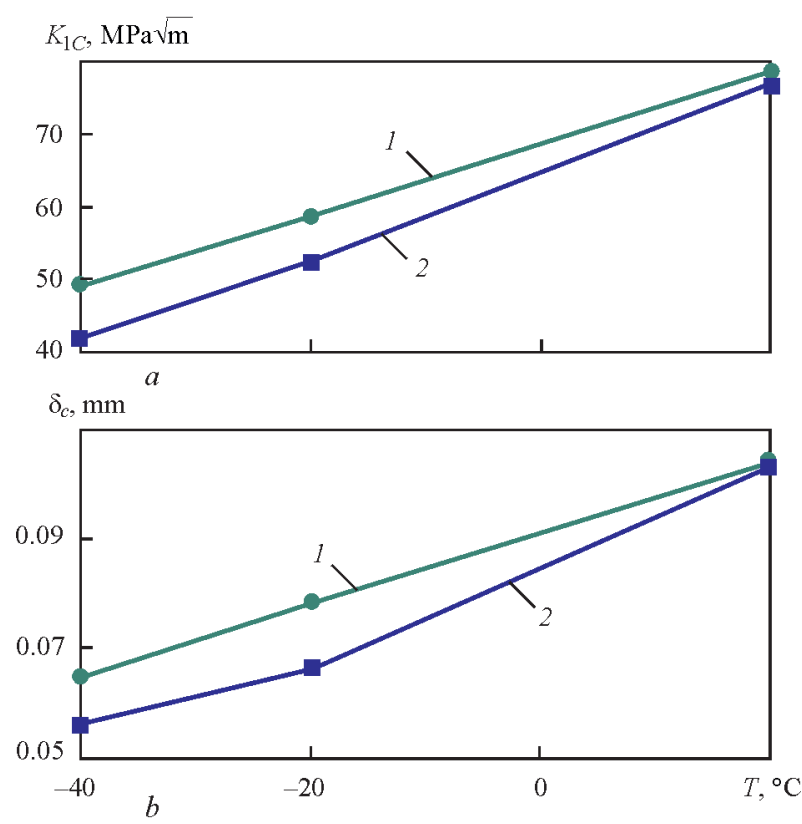

Figure 8. Dependence of values of critical stress intensity factor $K_{1 C}(a)$ and crack opening displacement $\delta_{c}(b)$ on the test temperature for weld metal of steel S460M welded joints made using flux-cored wire Megafil 821R (1) and electrodes UONI$13 / 55(2)$

cored wire of grade Megafil 821R, they amount to 47.6; 52.9 and $76.4 \mathrm{MPa} \sqrt{\mathrm{m}}$, which is also increased on average by $13.1 ; 1.2$ and $4.2 \%$ (Figure 9). At the same time, for the base metal the average values of the stress intensity factor $K_{1 C}$ amount to 49.7; 59.2 and $82.5 \mathrm{MPa} \sqrt{\mathrm{m}}$ at the test temperature of $-40,-20$ and $20{ }^{\circ} \mathrm{C}$ and they are by $11-15 \%$ higher than the values of this factor for the metal of welded joints.

The average values $\delta_{c}$ for weld metal in manual welding using electrodes UONI-13/55 (test temperatures $-40,-20$ and $20{ }^{\circ} \mathrm{C}$ ) are, respectively, equal to
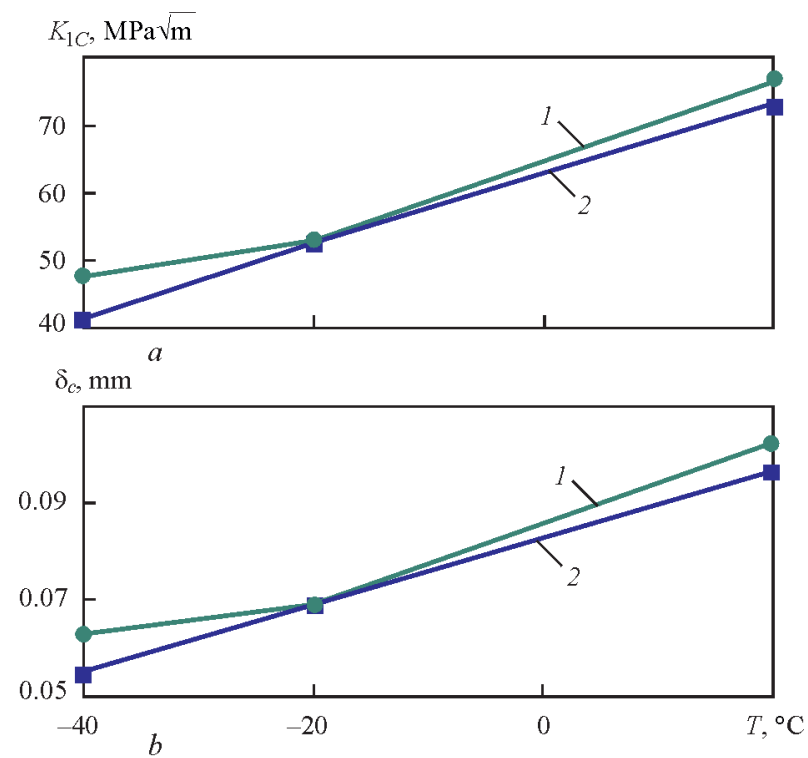

Figure 9. Dependence of values of critical stress intensity factor $K_{1 C}(a)$ and crack opening displacement $\delta_{c}(b)$ on the test temperature for HAZ metal of steel S460M welded joints made using flux-cored wire Megafil 821R (1) and electrodes UONI-13/55 (2) 
0.056; 0.066 and $0.103 \mathrm{~mm}$, and for the weld metal, produced using flux-cored wire of grade Megafil 821R at the similar temperature conditions of the tests, they amount, respectively, to $0.065 ; 0.078$ and $0.104 \mathrm{~mm}$. The same tendency is typical also for HAZ metal of welded joints. In welding using electrodes UONI$13 / 55$, the value $\delta_{c}$ for test temperatures $-40,-20$ and $20{ }^{\circ} \mathrm{C}$ is, respectively, $0.055 ; 0.069$ and $0.097 \mathrm{~mm}$, and for HAZ metal, produced using flux-cored wire of grade Megafil $821 \mathrm{R}$, they are, respectively, equal to $0.063 ; 0.069$ and $0.103 \mathrm{~mm}$ (Figure 9). The value $\delta_{c}$ for the base metal, the same as the values $K_{1 C}$, is higher than in the metal of welded joints and, respectively, equal to $0.066,0.078$ and $0.12 \mathrm{~mm}$. It should be noted that the ratio of values $\delta_{c}$ for the weld and HAZ metal of welded joints of steel S460M for different welding consumables are similar to the ratios of values $K_{1 C}$.

The common factor is that in mechanized welding using flux-cored wire Megafil 821R in the gas mixture $82 \% \mathrm{Ar}+18 \% \mathrm{CO}_{2}$ the metal of welded joints of steel S460M has a higher resistance to brittle fracture, than in manual arc welding using electrodes UONI$13 / 55$. These data are well correlated with the results of investigations of resistance to brittle fracture of welded joints similar in chemical composition to the steel S355J2.

\section{Conclusions}

1. It was found that in the range of cooling rates $7 \leq w_{6 / 5} \leq 15^{\circ} \mathrm{C} / \mathrm{s}$ of HAZ metal of model specimens of steel S460M the values of static strength, ductility and impact toughness are preserved at the level of values of base metal.

2. It was found that at low concentrations of diffusion hydrogen in the deposited metal, namely at $[\mathrm{H}]_{\text {diff }}=$ $=1.6 \mathrm{ml} / 100 \mathrm{~g}$, even in welding without preheating the steel $\mathrm{S} 460 \mathrm{M}$ is not prone to a delayed fracture.

3. It is possible to significantly improve the resistance to cold crack formation in the technological samples of steel S460M at the increased content of diffusion hydrogen in the deposited metal by reducing the value of residual stresses in welded joints to the level, not exceeding $0.5 \sigma_{\mathrm{y}}$ of steel ( $\leq 235 \mathrm{MPa}$ ) or by applying the preheating to $60^{\circ} \mathrm{C}$.

4. It was shown that in mechanized welding using flux-cored wire Megafil $821 \mathrm{R}$ in the gas mixture $82 \%$ $\mathrm{Ar}+18 \% \mathrm{CO}_{2}$ the metal of welded joints of steel S460M has a higher resistance to brittle fracture, than that in manual arc welding using electrodes UONI$13 / 55$.

1. Ufuah, E. (2013) Elevated temperature mechanical properties of butt welded connections made with high-strength steel grades S355 and S460M. In: Proc. of Int. Conf. on Design, Fabrication and Economy of Metal Structures (Miskolc, Hungary, April 24-26, 2013), 407-412.

2. Nazarov, A., Yakushev, E., Shabalov, I. et al. (2014) Comparison of weldability of high-strength pipe steels microalloyed with niobium, niobium and vanadium. Metallurgist, 7(9/10), 911-917.

3. (1993) Welded building structures. Vol. 1: Basis of structural design. Ed. by L.M. Lobanov. Kiev: Naukova Dumka.

4. Tylkin, M.A., Bolshakov, V.I., Odessky, P.D. (1983) Structure and properties of construction steel. Moscow: Metallurgiya.

5. Odessky, P.D., Molodtsov, A.F., Morozov, Yu.D. (2011) New efficient low-alloy steels for building metal structures. Montazhnye \& Spetsialnye Raboty $v$ Stroitelstve, 5, 20-25.

6. Bilyk, A.S., Kurashev, R.V., Gorbatenko, V.V. et al. (2013) Application of thermomechanically strengthened sheet products in welded metal structures. Promyslove Budivnytstvo ta Inzh. Sporudy, 4, 1-4.

7. Ragu Nathan, S., Balasubramanian, V., Malarvizhi, S. (2015) Effect of welding processes on mechanical and microstructural characteristics of high strength low alloy naval grade steel joints. Defence Technology, 11, 308-317.

8. Poznyakov, V.D., Zhdanov, S.L., Maksimenko, A.A. (2012) Structure and properties of welded joints of steel S390 (S355 J2). The Paton Welding J., 8, 6-10.

9. Sarzhevsky, V.A., Sazonov, V.Ya. (1981) Unit for simulation of welding thermal cycles on the base of machine MSR-75. Avtomatich. Svarka, 5, 69-70.

10. Hrivnak, I. (1984) Weldability of steels. Ed. by E.L. Makarov. Moscow: Mashinostroenie.

11. Mikhoduj, L.I., Poznyakov, V.D., Yushchenko, A.K. (2000) Resistance of 12KhN2MFDRA steel welded joints to a delayed fracture. The Paton Welding J., 11, 4-10.

12. Hall, U., Kukharova, Kh., Zut, V. (1978) Brittle fracture of welded structures. Ed. by I.V. Kudryavtsev et al. Moscow: Mashinostroienie.

13. Musiyachenko, V.F., Kasatkin, B.S., Zhdanov, S.L. et al. (1981) Examination of conditions of formation and propagation of cold cracks in high-strength steel welded joints by acoustic emission method. Avtomatich. Svarka, 7, 5-7.

Received 21.06.2016 